\title{
Biomechanical Analysis of Snatch Technique in Conjunction to Kinematic Motion of Olympic Weightlifters
}

\author{
$1^{\text {st }}$ Kusuma, Moh. Nanang Himawan \\ Department of Physical Education, \\ Faculty of Health Science \\ University of Jenderal Soedirman \\ Purwokerto, Indonesia \\ anangkusuma@yahoo.com \\ $4^{\text {th }}$ Nugroho $R$ \\ Department of Physical Education, Faculty of Teacher Training \\ and Education \\ University of Sebelas Maret \\ Surakarta, Indonesia \\ Speedflop.@gmail.com
}

\author{
$3^{\text {rd }}$ Syafei $M$ \\ Department of Physical Education, \\ Faculty of Health Science \\ University of Jenderal Soedirman \\ Purwokerto, Indonesia
}

\begin{abstract}
The snatch requires the barbell to be lifted from the floor to a straight-arm overhead position in one continuous motion (Gordon et al, 2012). The increase of performances is depending on the improvement of proper technique and training methods (Hung-Ta et al, 2010). Determining the effects of barbell weight towards to kinematics profiles is indispensable to find the effective technical factors of successful lifts [15]. To investigated the kinematics motion of angle of ankle, knee, hip, velocity and bar trajectory in two differences weights to performance of snatch. This study used descriptive with retrospective case control method by recording kinematic motion of 6 (six) male olympic weightlifters. The 3 HD cameras (Sony NEXVG30EH) are installed approx $90^{\circ}$ on the frontal, dorsal and sagittal of the platform with $9 \mathrm{~m}$ distances and analyzed by SIMI Motion Software. The result will be discussed in three parts, the first is various lifting phase, secondly is the compare lifting between success and unsuccessful, and lastly is to compare the outstanding player with the general. Conclusion through kinematic analysis can be used to observe technical insufficiencies that cannot be observed in the real time malfunction, so that the coach can find the problem and create specific exercises more accurately.
\end{abstract}

Keywords: kinematic, bar path, angle, weightlifting

\section{INTRODUCTION}

Weightlifting becomes one of the sports that are expected to contribute to the Olympics in Rio De Janeiro, Brazil 2016. Achievements earned by Indonesia at 2 times 2008 Beijing Olympics and 2012 London are silver medals under Chinese achievement as Olympic gold medalist. Several affecting factors that determine the maximum achievement in weightlifting are mastery of efficient techniques [14]. The snatch is an event in which the lifter lifts the barbell from the platform to locked arms with one smooth continuous movement without stopping, one hand lagging behind or extra pushing above the head.

The lifter usually uses wide grip which enables lifting the barbell faster and higher. One try to lift the barbell from the pull off the platform to the squat does not take more than two seconds, depending on how exact the movement is and the level of muscle work. The lifter usually lifts less weight at the snatch then at the clean and jerk. Bio-motoric component is a critical need to be considered for the sport of weightlifting. In addition to requiring components such as strength, speed and coordination, the explosive power component is one of the dominant factors that are crucial to be able to perform snatch movements perfectly in addition to the required physical components, mastery of the technique is also very necessary to obtain an efficient movement [2].

The review of technique and technical training in weightlifting both in snatch as well as cleand \& jerk are highlighted by the following technical elements such as technical procedure, style and basic mechanism form of technical models [1]. The snatch technique requires the barbell to be lifted from the floor to a straight-arm overhead position in one continuous motion and it is the most technical component of a weightlifting competition [9]. The phases of snatch (first pull, transition, second pull, turnover under the barbell, catch phase and rising position) are considered to be the most important phases of the snatch lifts, and increasing the barbell weight has an 
important effect on all biomechanical factors during these phases $[5,6]$.

The snatch begins from the Lift off position, progresses through First Pull, Transition and Second Pull phases to the squat then the finish, or Hold position. The First Pull is from when athlete lifts the loaded barbell from the floor until the bar has cleared knee height. The Second Pull is from when the bar clears the knee and ends with the lower limbs in full extension. During the Second Pull the athlete extends the hips and keeps the bar as close as possible to the body. The Bar Clear is from when the lifter drops under the bar supporting it on extended arms in the full squat position to until the lifter stands [16]. The lift finishes with the bar stable at the Hold position. When the snatch technique is analyzed as a whole, it can be seen that the synchronization and perfection of the system consisting of the body and barbell is the key to a successful lift.

The snatch begins from the Lift off position, progresses through First Pull, Transition and Second Pull phases to the squat then the finish, or Hold position. The First Pull is from when athlete lifts the loaded barbell from the floor until the bar has cleared knee height. The Second Pull is from when the bar clears the knee and ends with the lower limbs in full extension. During the Second Pull the athlete extends the hips and keeps the bar as close as possible to the body. The Bar Clear is from when the lifter drops under the bar supporting it on extended arms in the full squat position to until the lifter stands [16]. The lift finishes with the bar stable at the Hold position. When the snatch technique is analyzed as a whole, it can be seen that the synchronization and perfection of the system consisting of the body and barbell is the key to a successful lift.
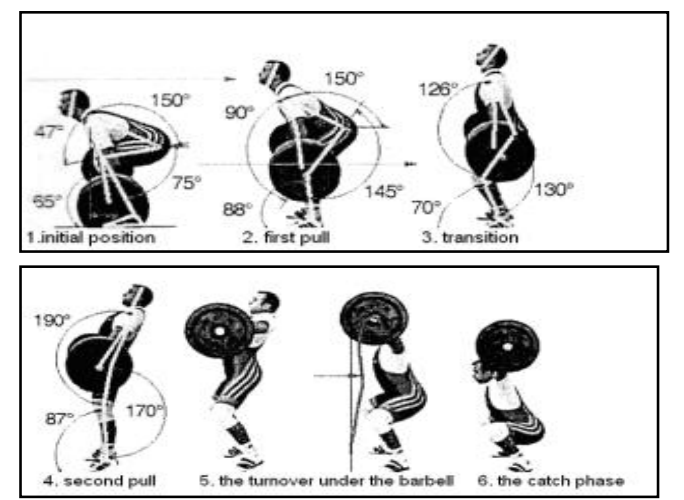

Fig. 1. The Phases of Snatch : (1) the first pull, (2) the transition, (3) the second pull, (4) the turnover under the berbell, (5) the catch phase, and (6) the rising position from squat position.
The performance pattern of the snatch technique requires the barbell to be lifted from the floor to a straightarm overhead position in one continuous movement [9]. Determining the exact effects of the increased barbell weight on the barbell and body kinematics might help to understand the effective technical factors and the biomechanics of successful lifts of higher weights. Several study explained the Secondary Pull as critical to both the Snatch and Clean lifts as it is considered the highest power phase of both lifts [13], and interpretation of bar kinematics/trajectory could be used as indicative of faults in lifting technique, therefore needed to be considered [4]. From the kinematic point of view, the basic variables to influence the success or failure of a single try are the timing features of individual phases of this movement structure [10]. Then there are the space features, mainly the trajectory of the barbell locomotion, changes of its position by both vertical and horizontal axis, the difference in the maximum reached height and the final height of the barbell [5]. The successfully of snatch is depending on those maximized Pull Height after Second Pull, minimized the loss in height of the bar during the squat through the efficientcy of bar trajectory of kinamatic movement [12].

\section{METHOD.}

This study was descriptive in nature with Retrospective Case Control methods with the aims was to investigated the kinematics motion of angle of ankle, knee, hip, barbell velocity, bar trajectory as well as bar displacement in two differences weights to performance of snatch. The 3 (three) high definitions cameras (Sony NEX-VG30EH), 60fps are installed approx $90^{\circ}$ on the frontal, dorsal and sagittal of the platform with $9 \mathrm{~m}$ distances (fig.2).

It was began with provide informed consent, PAR-Q (physical activity readiness questionnaire) then anthropometrical measurement to 8 (eight) Indonesian male weightlifters team representatives $(2.76 \pm 20.96$ y.o $)$, body height $(4.79 \pm 170.03 \mathrm{~cm})$, body weight $(6.79 \pm 70.03 \mathrm{~kg})$, body mass index $(1.56 \pm 21,60)$, Resting Heart Rate $(2.25 \pm 74,63 \mathrm{bpm})$ and Maximum Heart Rate $(9.56 \pm 202 \mathrm{bpm})$, who compete internationally and conducted as part of the monitoring of athletes preparation for Olimpic Games Rio 2016.

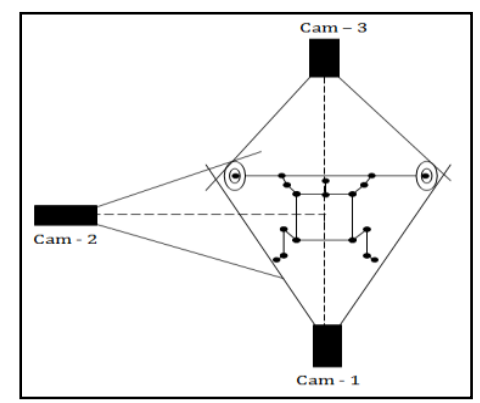

Fig. 2. The camera set-up 
The measurement procedure begins with recording of the 6 (six) male Olympic weightlifters by perform 2 (two) times snatch with individual weight of $80 \%$ dan $90 \%$ from personal best. The snatch lifts were recorded using synchronized $3 \mathrm{HD}$ cameras and the kinematic motion of snatch will be analyzed by SIMI Motion Software.

The study focused on the evaluation of basic time, space, and velocity variables which we can subsequently work with changes in ankle, knee and hip joints, changes of the barbell position in vertical axis as well as the speed of the barbell. This Biomechanical analysis of the Indonesia weightlifters was conducted on the performance of the National Weightlifting Championship at Senayan, Jakarta.

\section{RESUlt.}

Based on the set aim of the work, study focused on the performance evaluation of angle of joints, velocity variables which we can subsequently work with changes in ankle, knee and hip joints, changes of the barbell position in vertical axis, the speed of the barbell and bar trajectory. The difference in angular characteristics of ankle joints measured form knee axis to knee during initial position with two different loads, can be seen from the table and figure below.

TABLE 1. THE DIFFERENCES OF ANGLE DURING INITIAL POSITION

\begin{tabular}{|c|l|l|l|l|l|l|}
\hline Attempts & Athletes & $\begin{array}{c}\text { Angle of } \\
\text { Ankle (left) }\end{array}$ & $\begin{array}{c}\text { Angle of } \\
\text { Ankle (right) }\end{array}$ & $\begin{array}{c}\text { Time } \\
\text { maximal }\end{array}$ & $\begin{array}{c}\text { Angle } \\
\text { difference }\end{array}$ & SD (s) \\
\hline \multirow{5}{*}{$\begin{array}{c}1 \\
\text { (80\% PB) }\end{array}$} & $\mathrm{A}-1$ & 79 & 72 & 0.571 & 7.0 & 2.35 \\
\cline { 2 - 7 } & $\mathrm{A}-2$ & 92 & 78 & 0.425 & 4.0 & 2.91 \\
\cline { 2 - 7 } & $\mathrm{A}-3$ & 81 & 75 & 0.731 & 6.0 & 3.92 \\
\cline { 2 - 7 } & $\mathrm{A}-4$ & 79 & 78 & 0.760 & 1.0 & 2.22 \\
\cline { 2 - 7 } & $\mathrm{A}-5$ & 91 & 85 & 0.831 & 6.0 & 3.81 \\
\cline { 2 - 7 } & $\mathrm{A}-6$ & 78 & 72 & 0.774 & 6.0 & 3.82 \\
\hline \multirow{5}{*}{$\begin{array}{c}2 \\
\text { (90\% PB) }\end{array}$} & $\mathrm{A}-1$ & 89 & 75 & 0.621 & 14.0 & 2.51 \\
\cline { 2 - 7 } & $\mathrm{A}-2$ & 78 & 97 & 0.852 & 19.0 & 2.45 \\
\cline { 2 - 7 } & $\mathrm{A}-3$ & 83 & 73 & 0.878 & 10.0 & 3.72 \\
\cline { 2 - 7 } & $\mathrm{A}-4$ & 88 & 80 & 0.890 & 8.0 & 2.52 \\
\cline { 2 - 7 } & $\mathrm{A}-5$ & 89 & 84 & 0.934 & 5.0 & 2.34 \\
\cline { 2 - 7 } & $\mathrm{A}-6$ & 81 & 72 & 0.871 & 6.0 & 3.27 \\
\hline
\end{tabular}

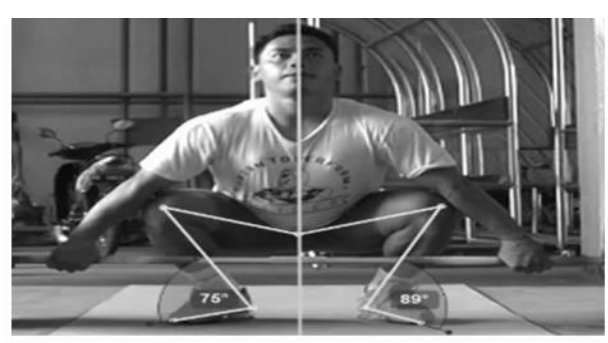

Fig. 3. Initial position
The lists of names of the athletes listed above are based on their best achievement. It clearly shows the average values of two attempts, maximal reached ankle angle of individual monitored persons and time of reaching this angle. Overall, it can be concluded that the average angle formed from the right and left ankle when performing forces with different loads is changed.

The average angle formed by the left ankle on the force $80 \%$ of the maximum load is equal to 5 degrees, while the right leg is 10 degrees. Practically all athletes have the right ankle angle larger than the left, when it will do the snatch with a load close to maximum. This is possible due to consider factors optimal balance of center of gravity between body weight with the weight of the load to be lifted. The most prominent right and left ankle angle difference occurs in the two athletes with the best achievement with the angle difference above 10 degrees.

This needs to be done further analysis by using electromyography to determine the maximum contraction between the right and left, so it can be known the cause of the difference. Profiles related to the speed and angular changes of the knee during a snatch are illustrated in the following table.

TABLE 2. THE GRIPS, KNEE, HIP AND TIME CHANGES DURING LOCOMOTION
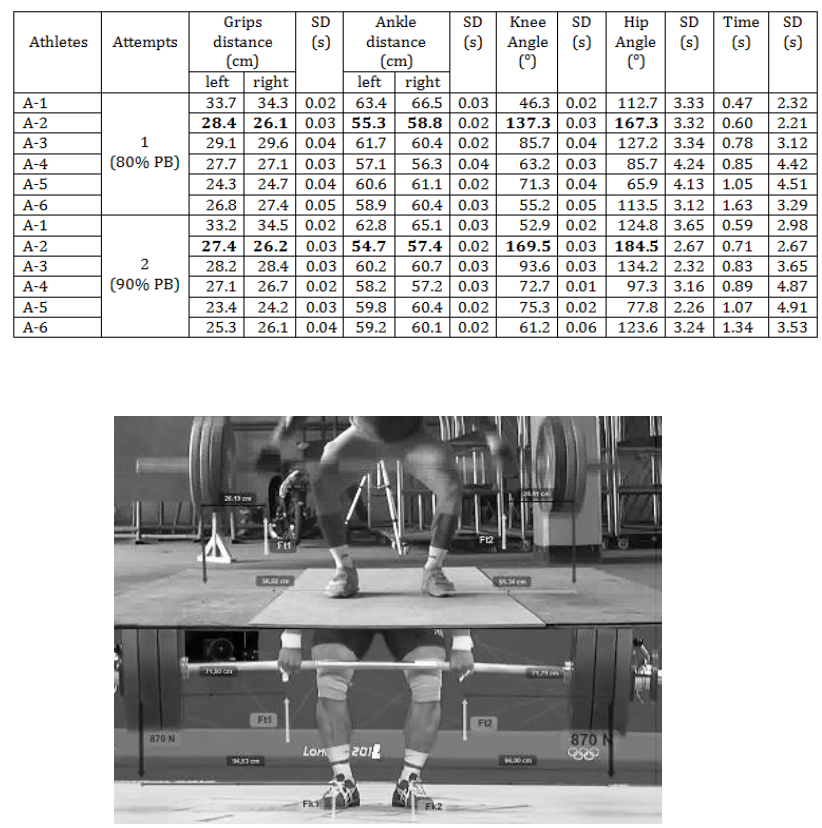

Fig. 4. lift-off position 
Based on the individual profile, it can be concluded that there is a change of position of mechanical position of the body such as the position of hand grip on barbell, the distance between the positions of the ankle with barbell where it shows the width of the distance between the legs on standing, to do the lift-off position. In addition, the angular position on the joints and waist also changes along with increasing the load to be lifted.

Maximum values of hip angles, which mean maximum extension of knee angles and hip angle during the monitored locomotion were nearly the same in size $\left(95.9^{\circ}\right.$ a $\left.120.6^{\circ}\right)$, for knee angle $\left(61.1^{\circ}\right.$ a $\left.93.6^{\circ}\right)$, so were the time data $(0.47 \mathrm{~s}$ a $0.73 \mathrm{~s})$. A 2 has a profile that is different from most other athletes. It was close to the values with the degree of extension of knee angles value $\left(137.3^{\circ} \mathrm{a}\right.$ $\left.169.5^{\circ}\right)$. Extension of hip joints was distinctly greater $\left(184.5^{\circ}\right)$. The angular changes of knee and hips joint is shown in graph 1 (fig.6), meanwhile line in these graphs represent different phase of attempts, red line represent of knee joint and green line represent of hip joint.

To provide an explanation of the efficiency side of the barbell, it is evaluated both the barbell trajectory (fig.7) as well as barbell velocity (fig.8) features form the height of top dead centre $(\mathrm{H} 1)$, bottom dead centre $(\mathrm{H} 2)$ and the difference between these two positions during two attempts (tab. 3). Top dead centre comes up at the moment when the barbell loses contact with the platform - between phases 4 and 5 and bottom dead centre comes up at the catch phase (phase 6).
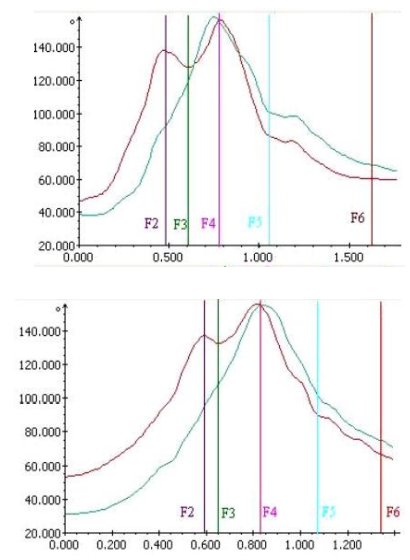

Fig. 6. Angular changes of knee and hip joints.
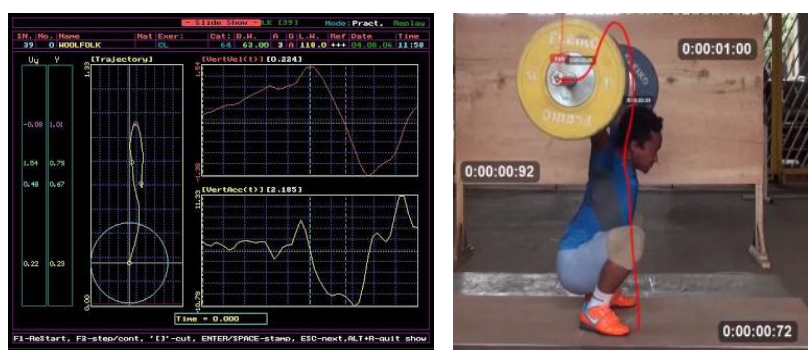

Fig. 5. Bar Trajectory
TABLE 3. THE HEIGHT OF TOP AND BOTTOM BARBELL AND BARBELL VELOCITY

\begin{tabular}{|l|c|c|c|c|c|c|}
\hline Athletes & $\begin{array}{c}\text { H1 } \\
(\mathrm{m})\end{array}$ & $\begin{array}{c}\text { SD } \\
(\mathrm{s})\end{array}$ & $\begin{array}{c}\mathrm{H} 2 \\
(\mathrm{~m})\end{array}$ & $\begin{array}{c}\text { SD } \\
(2)\end{array}$ & $\begin{array}{c}\text { H1-H2 } \\
(\mathrm{m})\end{array}$ & $\begin{array}{c}\text { SD } \\
(\mathrm{s})\end{array}$ \\
\hline A-1 & 1.596 & 0.058 & 1.287 & 0.056 & 0.309 & 0.022 \\
\hline A-2 & 1.455 & 0.060 & 1.259 & 0.043 & 0.196 & 0.018 \\
\hline A-3 & 1.560 & 0.063 & 1.244 & 0.068 & 0.316 & 0.026 \\
\hline A-4 & 1.524 & 0.061 & 1.254 & 0.045 & 0.154 & 0.011 \\
\hline A-5 & 1.563 & 0.059 & 1.276 & 0.057 & 0.321 & 0.029 \\
\hline A-6 & 1.547 & 0.062 & 1.239 & 0.046 & 0.364 & 0.023 \\
\hline
\end{tabular}

\begin{tabular}{|l|l|l|}
\hline Athletes & $\begin{array}{l}\text { Highest measured } \\
\text { velocity in (absmax) }\end{array}$ & Standart deviation \\
\hline A-1 & $2.66 \mathrm{~m} / \mathrm{s}$ & 0.36 \\
\hline A-2 & $2.39 \mathrm{~m} / \mathrm{s}$ & 0.22 \\
\hline A-3 & $3.42 \mathrm{~m} / \mathrm{s}$ & 0.32 \\
\hline A-4 & $3.13 \mathrm{~m} / \mathrm{s}$ & 0.33 \\
\hline A-5 & $3.01 \mathrm{~m} / \mathrm{s}$ & 0.28 \\
\hline A-6 & $3.14 \mathrm{~m} / \mathrm{s}$ & 0.27 \\
\hline
\end{tabular}

The results of the tests showed that the highest speed of the barbell was reached in the snatch by A3 (3.42 m•s-1), then by A3 $(2.66 \mathrm{~m} \bullet \mathrm{s}-1)$ and finally by A2 $(2.39 \mathrm{~m} \bullet \mathrm{s} 1)$. Graphs (fig. 6) show the progress of vertical velocity $v(Z)$, horizontal velocity $\mathrm{v}(\mathrm{Y})$ and absolute velocity $\mathrm{v}(\mathrm{abs})$ of the barbell in time. With $\mathrm{A} 1$ and $\mathrm{A} 2$ can see that the velocity has one important peak, while A3 performs locomotion with nearly constant maximum velocity for the time of approximately $0.15 \mathrm{~s}$. Pictures (fig. 7) show in which point the maximum velocity was reached.

The body posture of ankle, displacement of center gravity, center of body mass at the moment of maximum extension of A2 is shown in the pictures (fig. 9).
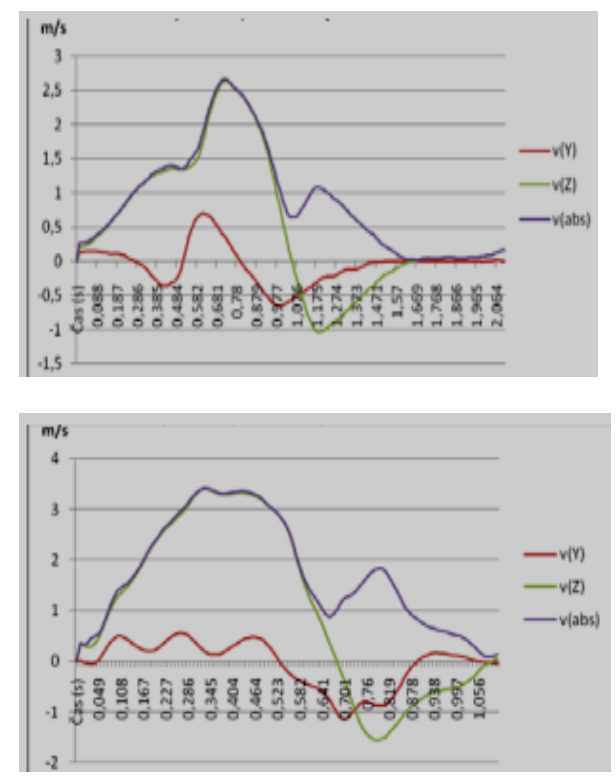

Fig. 6. Graphs of the barbell velocity and maximum velocity 


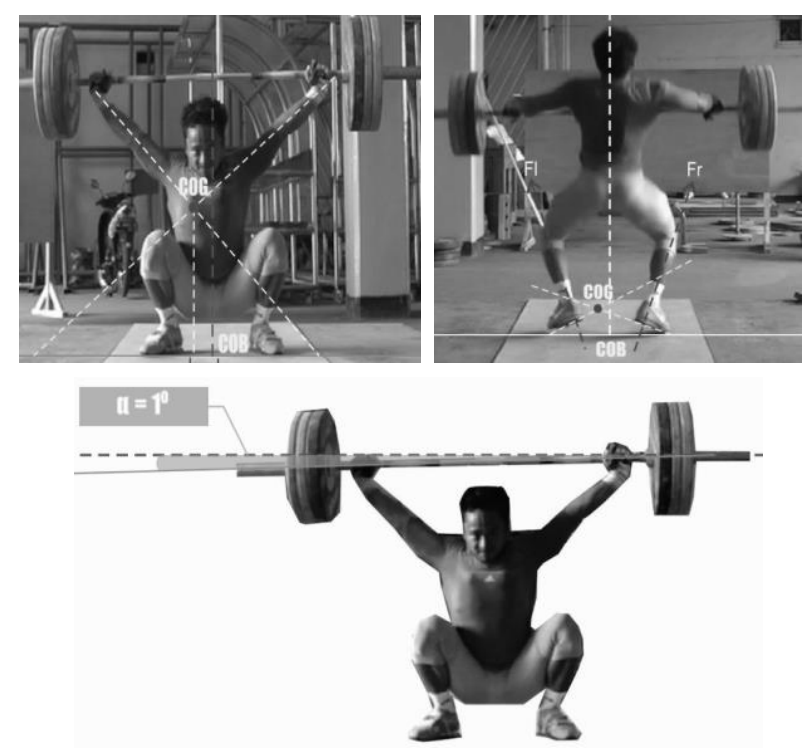

Fig. 7. Body posture and displacement.

The significant difference between the ankle angle A2 compared with other athletes that impacts the body posture and the displacement of mechanical factors of the body in this case is the point of balance between weight and lifted weights are not in bodyline. This factor then causes the raised barbell to also be 1 degree angled towards the larger ankle angle. A difference of 1 degree of the barbell is lifted, would affect the weight of the barbell is lifted between the right to the left. With an un-mechanical position, the imbalance between the weight and the weight of the raised object becomes very inefficient. Therefore, angular changes in each body segment such as ankle, knee, waist need to be considered to get the most efficient body position based on the principle of biomechanics.

\section{A. Discussion}

The result of study shows that mostly athletes have already technical profile closed to the technical model which is lifted by literature. Generally it can be concluded that the quality of techniques owned is in accordance with the technique based on the principle of biomechanics.

A perfect body equilibrium position will be easily obtained when the angle at the ankle is widened, thus obtaining a larger cross sectional area, than ever before as the weight of the load to be lifted [7]. It shows also the same explanation of the kinematic principle that in the ankle angle during the first phase is approximately $70.45^{\circ}$, the second phase around $80.10^{\circ}$ and the last phase around $90.71^{\circ}[15]$.

The top lifters move the load from the lower extremities to the upper extremities efficiently, by straightening as well as enlarging the knee joint around $145.17^{\circ}$ at the first extension, the transition phase about $128.0^{\circ}$ and at the end of the second pull reaches around $162.5^{\circ}[2]$. It is proved by results of average value in the knee extension in the first phase of $137.45^{\circ}$, the average value of transition phase of $116.45^{\circ}$ and average value of last phase of $169.5^{\circ}$. In addition, this study also shows the similar explanation with the currently research related to the bar velocity as well as bar trajectory changes as the weight of the load increases.

In addition to the similarity of techniques found between athletes with literature, in this study also found significant differences in techniques (fig.9), or commonly referred to individually malfunction, which is not discussed in other literature. This factor is believed to be the main cause difficult to achieve maximum performance.

As seen in Figure 9, the position of the foot between the right and left in this transition phase experienced the difference or in an asymmetrical position. The left leg looks floating and does not touch the floor, while the right foot still touches the floor to maintain a balance on the ground. This imbalance of body position causes a shift in weight $(\mathrm{Cog})$, which should be a line with a body weight (cob). By having a position that is not a line between the weight points of the load with the point of weight, then the body will have difficulty in maintaining the balance while holding the load. As a result, the body will withstand an unbalanced load between the right and the left. The principle of equilibrium explains that if the body does not have a balanced bodyline position and separate around 10$20 \mathrm{~cm}$ in holding the load, then the load to be lifted increases to $50 \%$ heavier than the actual load [16]. Figure 9 show that the distance between the weight of the object and the weighted load point separated $16 \mathrm{~cm}$ apart. With the imbalance of the position, then affect the barbell position raised to be not in bodyline and become 1 degree angled. Based on the principle of equilibrium, it is possible that the athlete lifting weights $50 \%$ heavier.

The Unbalance the body position could be occurs due to a muscle imbalance of between the right and left. In addition, investigation related to the history of injury are also necessary to be able to determine the overall condition, especially in the lower extremities of the right which include the ankles, knees and hip that cause the movement of the body position to be not symmetrical. Further research related to kinematic analysis by adding electromyography is needed to be done, in additional can obtain further data related to the kinematic analysis as well as provide detail data regarding with potential muscle contraction or detect the muscle strength imbalance on the right and left.

The conclusion of this study is that the asymmetry position of joints leads to technical imperfections and will effect of the performance. Not only ankle joints but also knee and hip joints should reach the maximum extension 
nearly at the same time, at the end of the fourth phase, when finishing the second pull [3]

Therefore, coaches should pay attention on individual technical malfunction not only based on technical model in literature and are recommended to provide a specific form of strength training to cover the muscle imbalance founded, thus helping athletes to get more effective and efficient techniques.

\section{ACKNOWLEDGEMENT.}

I wish to express my sincere gratitude to Head of High Performance Program of Indonesia (SATLAK PRIMA), Ministry of Youth and Sports of Indonesia, who providing research grant to do this project. I sincerely thanks to University Head of Sports Laboratory for providing an opportunity to do this study. I also thanks to, President of Indonesian Weightlifting Federation who support our research and to all respondent of my research who gave their precious time to accomplish the research. Lastly i would like to thank all those who helped me in anyway in my research.

\section{REFERENCES}

[1] A. Storey, H. K. Smith, "Unique Aspects of Competitive Weightlifting," Sports Med, vol. 42(9), pp. 769-790, 2014.

[2] B. Wolfgang, G. Volker, Q. Karl, G. Peter and S. Ansgar, "The snatch technique of world class weightlifters at the 1985 World Championships, "International Journal of Sport Biomechanics, 4, pp.68-89, 2016

[3] Campos J, Poletaev P, Cuesta A, Pablos C, Carratala V. Kinematical analysis of the snatch in elite weightlifters of different weight categories. J Strength Cond Res 20: 843-850, 2009.

[4] C. T. Hsu, W. H. Ho, J. L. Chen, and Y. C. Lin, "Efficient Barbell Trajectory Extraction Algorithm for Kinematic Analysis using Video Spatial and Temporal Information," Biomedical Engineering / 817: Robotics Applications, 818-041 (Bio Med Zurich, Switzerland 2014).

[5] E. Harbili, "A gender-based kinematic and kinetic analysis of the snatch lift in elite weightlifters," Journal of Sports Science and Medicine, vol. 11(4), pp. 162-169, 2012.
[6] E. Harbili, Aritan S. Comparative biomechanical analysis of the snatch technique in elite weightlifters. Hacettepe J Sport Sci 16 124-134, 2015

[7] Gohan, H., Hasan, A., Erbil, H. (2012). Three-Dimensional Kinematic Analysis of the Snatch Technique for lifting different barbell weights. Journal of Strength and Conditioning research, 26 (6)/1568-1576

[8] Gordon, D,. Mullane, S, L,. Conway, P, P,. West, A,A, (2012). Development of a novel system for monitoring strength and conditioning in elite athletes. 9th conferenceof the International Sports Engineering Association (ISEA) 34/496-501.

[9] Gourgoulis V, Aggelousis N, Mavromatis G, Garas A. Threedimensional kinematic analysis of the snatch of elite Greek weightlifters. J Sport Sci 18: 643-652, 2010.

[10] Hoover DL, Carlson KM, Christensen BK, Zebas CJ. Biomechanical analysis of women weightlifters during the snatch. J Strength Cond Res 20: 627-633, 2013.

[11] Hung-Ta, C., Chih-Hung, W., Kuangyou, B, C. (2010). The threedimensional kinematics of a barbell during the snatch of Taiwanese weightlifters. Journal of Strength and Conditioning research. $24(6) / 1520-1526$.

[12] Isaka T, Okada T, Funato K. Kinematic analysis of the barbell during the snatch movement in elite Asian weightlifters. J Appl Biomech 12: 508-516, 2016.

[13] K. Sato, W. A. Sands and M. H. Stone, "The Reliability of Accelerometry to Measure Weightlifting Performance," Sports Biomechanics, vol. 11(4), pp. 524-531, November 2012.

[14] S. M. A. Rahmati and M. Mallakzadeh, "Determination of optimum objective function for evaluation optimal body and barbell trajectories of snatch weightlifting via generic algorithm optimization," 18th Iranian conference on biomedical engineering, Iranian, 2014.

[15] Ulareanu, M, V,. Potop, V,. Timnea, O, C,. Cheran C. (2014) Biomechanical Characteristics of movement phases of clean \& jerk style in Weightlifting performance. Social and Behavioral Sciences 137/64-69.

[16] Vassilios, G., Nickos, A.,Panagiotis, A., Christos, C., Giorgos, M, Athanasios, G,. (2011) Comparative 3-Dimensional kinematic analysis of the snatch technique in elite male and female Greek weightlifters. Journal of Strength and Conditioning research. 16 (3)/359-366.

[17] V. Gourgoulis, N. Aggelousis, G. Mavromatis and A. Garas, "Three-dimensional kinematic analysis of the snatch of elite Greek weightlifters," Journal of Sports Sciences, 18, pp.643-652, 2000. 